University of Nebraska - Lincoln

DigitalCommons@University of Nebraska - Lincoln

USDA National Wildlife Research Center - Staff Publications
U.S. Department of Agriculture: Animal and Plant Health Inspection Service

2018

\title{
Evaluation of the palatability and toxicity of candidate baits and toxicants for mongooses (Herpestes auropunctatus)
}

\author{
Robert T. Sugihara \\ USDA National Wildlife Research Center \\ William C. Pitt \\ Smithsonian Conservation Biology Institute \\ Are R. Berentsen \\ USDA National Wildlife Research Center, Are.R.Berentsen@aphis.usda.gov \\ Cynthia G. Payne \\ USDA National Wildlife Research Center
}

Follow this and additional works at: https://digitalcommons.unl.edu/icwdm_usdanwrc

Part of the Life Sciences Commons

Sugihara, Robert T.; Pitt, William C.; Berentsen, Are R.; and Payne, Cynthia G., "Evaluation of the palatability and toxicity of candidate baits and toxicants for mongooses (Herpestes auropunctatus)" (2018). USDA National Wildlife Research Center - Staff Publications. 2061.

https://digitalcommons.unl.edu/icwdm_usdanwrc/2061

This Article is brought to you for free and open access by the U.S. Department of Agriculture: Animal and Plant Health Inspection Service at DigitalCommons@University of Nebraska - Lincoln. It has been accepted for inclusion in USDA National Wildlife Research Center - Staff Publications by an authorized administrator of DigitalCommons@University of Nebraska - Lincoln. 


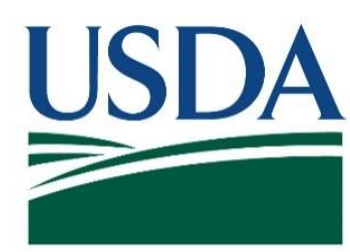

U.S. Department of Agriculture

U.S. Government Publication

Animal and Plant Health Inspection Service

Wildlife Services 


\title{
Evaluation of the palatability and toxicity of candidate baits and toxicants for mongooses (Herpestes auropunctatus)
}

\author{
Robert T. Sugihara ${ }^{1} \cdot$ William C. Pitt $^{2} \cdot$ Are R. Berentsen $^{3} \cdot$ Cynthia G. Payne ${ }^{1}$
}

Received: 9 May 2017 / Revised: 27 September 2017 / Accepted: 24 November 2017

(C) This is a U.S. Government work and not under copyright protection in the US; foreign copyright protection may apply 2017

\begin{abstract}
The small Indian mongoose (Herpestes auropunctatus) is an invasive pest species responsible for damage to native avian, reptile, and amphibian species on Hawaii, Croatia, Mauritius, and several Caribbean Islands, among other regions. Mongoose control has been pursued through a variety of means, with varying success. One toxicant, diphacinone, has been shown to be effective in mongooses and is co-labeled in a rodenticide bait for mongoose control in Hawaii; however, preliminary observations indicate low performance as a mongoose toxicant due likely to poor consumption. We evaluated the efficacy and palatability of 10 commercial rodenticide baits, technical diphacinone powder, and two alternative acute toxicants against mongooses in laboratory feeding trials. We observed poor acceptance and subsequent low overall mortality, of the hard grain-based pellets or block formulations typical of most of the commercial rodenticide baits. The exception was Tomcat ${ }^{\circ}$ bait blocks containing $0.1 \%$ bromethalin, an acute neurotoxin, which achieved up to $100 \%$ mortality. Mortality among all other commercial rodenticide formulations ranged from 10 to $50 \%$. Three-day feedings of $0.005 \%$ technical diphacinone formulated in fresh minced chicken achieved 100\% mortality. One-day feedings of para-aminopropiophenone (PAPP), a chemical that reduces the oxygen-carrying capacity of the blood, achieved $100 \%$ mortality at concentrations of 0.10 to $0.15 \%$. Bait acceptance of two sodium nitrite formulations (similar toxic mode of action as PAPP) was relatively poor, and mortality averaged $20 \%$. In general, commercially produced rodenticide baits were not preferred by mongooses and had lower mortality rates compared to freshly prepared meat bait formulations. More palatable baits had higher consumption and achieved higher mortality rates. The diphacinone bait registered for rat and mongoose control in Hawaii achieved 20\% mortality and was less effective than some of the other commercial or candidate fresh bait products evaluated in this study.
\end{abstract}

Keywords Herpestes auropunctatus $\cdot$ Invasive species $\cdot$ Small Indian mongoose $\cdot$ Toxicant

Small Indian mongooses (Herpestes auropunctatus), originally introduced to Hawaii for rat control in sugarcane fields in 1883 by sugar planters, are serious predators of native wetland, seabird, and upland forest avian species in the Hawaiian islands (Bryan 1938; Baldwin et al. 1952; Keith et al. 1990; USFWS 1999; Hays and Conant 2007). In addition,

Are R. Berentsen

Are.R.Berentsen@aphis.usda.gov

1 USDA APHIS WS National Wildlife Research Center, 210 Amau'ulu Rd, Hilo, HI 96720, USA

2 Smithsonian Conservation Biology Institute, 1500 Remount Rd, Front Royal, VA 22630, USA

3 USDA APHIS WS National Wildlife Research Center, 4101 LaPorte Ave, Fort Collins, CO 80521, USA mongooses have been introduced as a biocontrol agent to various islands in the Caribbean, (Nellis and Everard 1983; Hoagland et al. 1989), portions of Europe (Barun et al. 2011, 2010; Tvrtkovic and Krystufek 1990), Mauritius (Roy et al. 2002) and Japan (Okinawa and Amami) (Yamada and Sugimura 2004) where they have been implicated in the decline of numerous native avian, mammal, reptile, and amphibian species. Mongooses are well established across most of the main Hawaiian Islands (Hawaii, Oahu, Maui, and Molokai) where they pose a threat to the eggs and nestlings of native ground-nesting birds (Tomich 1986). Early introductions of mongooses on the island of Kauai were not successful. Kauai harbors critical bird habitat that is currently thought to be free from the threat of mongoose predation. However, a road-killed lactating adult female mongoose was found on Kauai in 1976 (Tomich 1986) with numerous sighting reports over the past few decades throughout the island. Multiple 
sightings in early 2012 resulted in the capture of two adult mongooses near Nawiliwili and Lihue, Kauai in May 2012 (Kauai Invasive Species Committee [KISC], unpublished data). An additional adult male mongoose was captured at the Lihue air cargo facility in October 2016 (KISC, unpublished data).

The threat of accidental or intentional introductions to other mongoose-free islands in the Hawaiian chain and other Pacific locations highlights the need for a comprehensive menu of control techniques, including attractive and palatable baits and effective toxicants, to quickly respond to reported sightings or incipient mongoose populations (Phillips and Lucey 2016) under a diversity of scenarios.

Mongooses also present a health risk to humans as hosts of leptospirosis in Hawaii (Alicata and Breaks 1943; Alicata 1958; Minette 1964; Higa and Fujinaka 1976; Wong et al. 2012) and the Caribbean (Pimentel 1955a, b; Everard et al. 1976), and as a rabies reservoir on several islands in the Caribbean (Everard and Everard 1992; Zieger et al. 2014; Berentsen et al. 2015). Hawaii has the highest prevalence of leptospirosis in humans requiring medical treatment in the USA (Wong et al. 2012). The high populations (up to 5.7/ ha; Tomich 1979) of mongooses and their habitation near abundant streams and ponds used for recreational activities is likely a significant route of transmission of the bacteria from mongooses to humans. Prevalence of leptospirosis in mongooses has been estimated at $18.4 \%$ in some areas of Hawaii, compared with up to $26.7 \%$ for some rodent species (Wong et al. 2012).

A myriad of techniques, including shooting, trapping, toxicants, etc., have been deployed around the world to protect rare and endangered ground-nesting native birds, invertebrates, reptiles and amphibians from mongoose predation (Pimentel 1955b; Everard and Everard 1992; Barun et al. 2011), with mixed results.

Toxicants have the potential to provide a cost-effective, low-maintenance, and large-scale method for mongoose control under application scenarios where trapping, exclusion, or other non-toxic methods are impractical or insufficient. Most of the early non-selective toxicants (strychnine, thallium sulfate, sodium fluoroacetate [Compound 1080], etc.), used primarily to control rodents in sugarcane fields, have never been evaluated for mongoose control and have been discontinued due to environmental concerns.

An early study by Keith et al. (1990) resulted in a special local need (SLN) registration of diphacinone $(0.00025 \%$ active ingredient) formulated with fresh lean hamburger meat for control of mongoose depredation on ground-nesting native birds in Hawaii. The fresh bait was placed in bait stations to minimize exposure to non-target animals (i.e., groundforaging birds and feral cats/dogs/pigs). Although the fresh bait was efficacious against mongooses, numerous logistical concerns (bait formulation, limited field bait life, frequent replenishment) resulted in its limited use and eventual expiration/non-renewal of the EPA registration. The method was also less successful in areas with low mongoose density or high alternative prey density. Currently, a $0.005 \%$ diphacinone rodenticide bait block (Ramik ${ }^{\circledR}$ Mini Bars, EPA Reg. No. 613282-26) is approved for use in bait stations to control mongoose in conservation areas in Hawaii under a SLN supplemental label. A diphacinone pelleted rodenticide bait (Diphacinone-50; EPA Reg. No. 56228-35) was also recently approved for broadcast application in conservation areas, though it is not labeled for control of mongoose. The attractiveness and palatability of these bait matrixes to mongooses have not been assessed in controlled feeding trials. Chlorophacinone $\left(0.005 \%\right.$ a.i.) (Rozol ${ }^{\circledR}$ Pellets- EPA SLN No. HI-080002) is also approved for field use against rodents in Hawaiian fruit and nut orchards, sugarcane fields, and selected field seed (corn, soybean) crops (Pitt 2008). The diphacinone and chlorophacinone commercial rodenticide baits are routinely used to control rodents in locations coinhabited by mongooses. Mongooses have been known to visit the rodenticide bait stations, but the operational efficacy of these baits for free-ranging mongooses has been questionable or unknown, and (aside from use of Ramik ${ }^{\circledR}$ Mini Bars in Hawaii) their intentional use for mongoose control is currently not legal under EPA label restrictions.

Other registered rodenticide baits are routinely used in and around industrial, commercial, and agricultural food commodity storage, sorting, processing, and packing structures in Hawaii to control rodent infestation, reduce product and structural damage, and address health and sanitation concerns. Mongooses, attracted by the alternate food sources, forage near and within certain open commercial structures and are an equal depredation and health concern.

Limited field research has been conducted on the efficacy of rodenticides on free-ranging mongooses. Smith et al. (2000) documented a decrease in mongoose populations following diphacinone bait application relative to control plots, but no residue analysis was performed and no evidence was presented to demonstrate that mongooses had eaten the bait and not simply perished from scavenging dead rats. Further, Young et al. (2013) describe the use of a predator-proof fence combined with the use of diphacinone bait to remove mongooses from Ka'ena point, Hawaii. Lethal control (trapping) had also been employed during fence construction prior to initiation of baiting. Evidence was lacking on whether "eradication" of mongooses from within the fenced area was a result of direct bait consumption by mongooses or other factors (i.e., secondary poisoning; Young et al. 2012). Marginal efficacy of the commercially available rodenticide bait identifies the need to evaluate new toxicants.

We evaluated 10 currently registered rodenticide bait products approved for use in Hawaii as well as encapsulated dry Para-aminopropiophenone (PAPP), sodium nitrite, and 
technical grade diphacinone in various concentrations using fresh minced chicken as the bait substrate (Table 1). Commercial rodenticide baits were in hard pellet, block, or soft bait (in paper or plastic packets) form.

\section{Methods}

\section{Mongoose procurement, housing, and maintenance}

Mongooses were live captured using $12.5 \times 12.5 \times 18 \mathrm{~cm}$ cage traps (Tomahawk®, Hazelhurst, WI) in agricultural, conservation, and forested areas around Hilo, Hawaii. Mongooses were collected and housed (harbored) following Hawaii Department of Agriculture official permit for use of mongooses for research purposes. All areas targeted for trapping were in areas without recent ( $<10$ years) known use of rodenticides. Mongooses were transported in-trap to the NWRC Hawaii Field Station and dusted for ectoparasites with Drione ${ }^{\circledR}$ (synergized natural pyrethrum) before transferring them to the testing facility. All mongooses were at least 3-4 months of age (i.e., sexually mature). Individual mongooses were temporarily housed $(\leq 5$ days) in stainless steel cages $(42 \times 24 \times$ $17.5 \mathrm{~cm}$ ) and provided with a daily maintenance ration of dry cat food (Meow Mix ${ }^{\circledR}$, Del Monte Foods) and water ad libitum. Rat (Rattus and $R$. exulans) carcass (previously trapped in known rodenticide-free areas and frozen) and raw chicken wings/thighs (previously frozen) were supplemented every second day.

All products tested are listed in Table 1. Commercial rodenticides were obtained from the bait manufacturer or local suppliers. Technical and candidate toxicants were procured directly from the chemical manufacturer. Frozen chicken tenders were purchased locally. Mongooses were randomly assigned to treatment groups of 10 animals (five males, five females) with an untreated control group of two mongooses ( $1 \mathrm{~m}, 1 \mathrm{f}$ ) matched to each treatment group. Mongooses were transferred to larger individual stainless steel modified rabbittype cages $(60 \times 60 \times 40 \mathrm{~cm})$ for the feeding trials and allowed at least 2 days to acclimate to the test cages before the feeding trials began.

\section{Commercial rodenticides}

Diphacinone and chlorophacinone are "first generation" anticoagulants that require sustained feeding over multiple days to affect mortality. In this study, we tested palatability and efficacy of commercial rodenticide baits containing $0.005 \%$ diphacinone (formulated as Ramik Green ${ }^{\circledR}$ pellets and Ramik ${ }^{\circledR}$ Mini Bar blocks) and $0.005 \%$ chlorophacinone (Rozol@ pellets). "Second generation" anticoagulants are more acutely toxic and a lethal dose can be consumed in a single

Table 1 Commercial and experimental toxicants and baits offered to mongooses

\begin{tabular}{|c|c|c|c|}
\hline Product & Bait type & Active ingredient & A.I. conc. $(\%)$ \\
\hline \multicolumn{4}{|l|}{ Commercial rodenticide baits } \\
\hline Ramik® Green & Pellets & Diphacinone & 0.005 \\
\hline Ramik@ Green & Mini bars & Diphacinone & 0.005 \\
\hline Rozol® & Pellets & Chlorophacinone & 0.005 \\
\hline Brodifacoum $25 \mathrm{~W}$ & Pellets & Brodifacoum & 0.0025 \\
\hline Resolv® & Soft bait packs & Bromadiolone & 0.005 \\
\hline Boot Hill@ & Pellets place packs & Bromadiolone & 0.005 \\
\hline Fast Draw ${ }^{\circledR}$ & Soft bait packs & Difethialone & 0.0025 \\
\hline Tomcat ${ }^{\circledR}$ Mouse and Rat Killer & Bait blocks & Bromethalin & 0.01 \\
\hline $\operatorname{Terad}_{3}{ }^{\circledR}$ & Bait blocks & Cholecalciferol & 0.075 \\
\hline $\operatorname{Terad}_{3}{ }^{\circledR}$ & Pellets & Cholecalciferol & 0.075 \\
\hline \multicolumn{4}{|l|}{ Diphacinone technical material } \\
\hline Diphacinone, dry, technical grade & Minced chicken & Diphacinone & 0.005 \\
\hline \multicolumn{4}{|l|}{ Additional candidate toxicants } \\
\hline PAPP NZ, encapsulated dry, $53 \%$ technical grade & Minced chicken & $\begin{array}{l}\text { Encapsulated dry } 53 \% \text { technical } \\
\text { Para-aminopropiophenone }\end{array}$ & $0.075,0.10,0.15$ \\
\hline $\begin{array}{l}\text { PAPP JPN, formula 1: encapsulated dry, } 71.6 \% \\
\text { technical grade }\end{array}$ & Minced chicken & $\begin{array}{l}\text { Encapsulated dry } 71.6 \% \text { technical } \\
\text { Para-aminopropiophenone }\end{array}$ & 0.15 \\
\hline $\begin{array}{l}\text { PAPP JPN, formula 2: encapsulated dry, } 68.3 \% \\
\text { technical grade }\end{array}$ & Minced chicken & $\begin{array}{l}\text { Encapsulated dry } 68.3 \% \text { technical } \\
\text { Para-aminopropiophenone }\end{array}$ & 0.15 \\
\hline Sodium nitrite, encapsulated dry & Minced chicken & Sodium nitrite & 5.0 \\
\hline Sodium nitrite, encapsulated peanut butter slurry & Minced chicken & Sodium nitrite & 5.0 \\
\hline
\end{tabular}


feeding; we evaluated $0.0025 \%$ brodifacoum (Brodifacoum $25 \mathrm{~W}$ pellets, Bell Laboratories), $0.005 \%$ bromadialone (Boot Hill ${ }^{\circledR}$ pellet packets and Resolv ${ }^{\circledR}$ soft packs), and $0.0025 \%$ difethialone (Fast Draw ${ }^{\circledR}$ soft bait packs).

Bromethalin is an acute neurotoxin. We tested the $0.01 \%$ bromethalin rodenticide formulation Tomcat ${ }^{\circledR}$ Mouse and Rat Killer. Cholecalciferol (vitamin $\mathrm{D}_{3}$ ) toxicosis causes hypercalcemia, affecting the central nervous system, muscles, gastrointestinal tract, cardiovascular system, and kidneys, leading to death. We tested $0.075 \%$ cholcalciferol formulated as $\operatorname{Terad}_{3}{ }^{\circledR}$ pellets and bait blocks.

Studies by Keith et al. (1990) found 3 to 5 days of continuous feeding is required to affect anticoagulant (diphacinone) toxicity in mongooses. Similar results were found with chlorophacinone in rats (Pitt 2008). However, time to death from the other, nonanticoagulant, and commercial toxicants in this study was unknown. In the absence of such data, we offered all commercial rodenticide baits for 5 consecutive days.

Approximately $50 \mathrm{~g}$ (an amount in excess of the average daily consumption of maintenance diet for mongooses held in quarantine during current and previous trials) of each commercial bait product was offered to mongooses in no-choice feeding trials, but each mongoose was supplemented with 20 $30 \mathrm{~g}$ of rat or raw chicken every 2 nd day to avoid fooddeprived lethargy and potential starvation. The control group received similar amounts of the regular daily ration of maintenance diet.

\section{Additional candidate toxicants}

To contrast with the hard grain-based matrix of the rodenticide product currently available for commercial use (Ramik ${ }^{\circledR}$ Mini Bars $0.005 \%$ diphacinone blocks), we tested technical diphacinone mixed in a minced chicken formulation to $0.005 \%$ concentration. The technical diphacinone was mixed with $2 \%$ corn oil ( $2 \%$ of overall minced chicken weight) then added to the minced chicken and mixed for $5 \mathrm{~min}$ in an electric blender and an additional 5 min manually. One test group of 10 mongooses was offered the minced chicken formulation for 1 day, and another test group was exposed for 3 days. As with commercially-formulated anticoagulant baits, signs of toxicity were not expected except after multiple days of feeding. Approximately $50 \mathrm{~g}$ of the treated minced chicken was offered to each treatment group mongoose per day. Control group mongooses were each offered $50 \mathrm{~g}$ minced chicken formulated with corn oil only.

Para-aminopropiophenone (PAPP) is a methemoglobinforming chemical that reduces the oxygen-carrying capacity of the blood and, at toxic doses, has been shown to be humane and quick acting in trials in Australia (foxes, feral dogs/cats) and New Zealand (stoats, ferrets, and feral cats) (Savarie et al. 1983; Fisher et al. 2005; Fisher and O'Connor 2007; Eason et al. 2010a, 2014). PAPP's relatively lower toxicity to rodents has attracted Japanese interest in testing PAPP against mongooses due to the presence of an endangered species of rabbit and two species of native rats in Okinawa and Amami Oshima islands in the Japanese archipelago (Yamada and Sugimura 2004). We obtained a sample of encapsulated dry 53\% technical grade PAPP from a New Zealand laboratory (Connovation, East Tamaki, NZ) and mixed trial batches with minced chicken and $2 \%$ corn oil to concentrations of 0.075 , 0.10 , and $0.15 \%$ active ingredient following similar mixing procedures as the fresh minced chicken diphacinone baits. We also tested two PAPP formulations from Japan (INOA Corp, Tokyo, Japan): $71.6 \%$ dry encapsulated powder (Japan formulation 1) and $68.3 \%$ encapsulated dry technical grade PAPP (Japan formulation 2). These were also incorporated into minced chicken at concentrations of $0.15 \%$ active ingredient. The encapsulated particle size and percent inert compounds (binders, etc.) were not disclosed by either manufacturer.

Sodium nitrite, a commonly used food preservative and ingredient in commercial fertilizers, is another methemoglobinemia-inducing chemical that has been investigated as a potential vertebrate pesticide (Lapidge et al. 2012). Australian researchers have conducted studies on the use of sodium nitrite to control feral hogs (Lapidge et al. 2012, 2009; Cowled et al. 2008). Hog-Gone® pelleted bait containing sodium nitrite was developed in Australia for feral pigs and is being evaluated for use in the USA (Campbell 2012). Witmer (2013) evaluated sodium nitrite as a rodenticide in the USA and preliminary results suggest efficacy as a toxicant, although rats seemed to be the least sensitive relative to other rodent species evaluated. We evaluated two doubleencapsulated sodium nitrite products (Animal Control Technologies, Somerton, Victoria, Australia), a dry powder ( $90.0 \%$ a.i.), and a peanut butter slurry ( $50.0 \%$ a.i.) formulated in minced chicken at a concentration of $5.0 \%$ active ingredient.

For the PAPP and sodium nitrite trials, mongooses were exposed to $50 \mathrm{~g}$ of the formulated minced chicken bait for a single 24-h feeding episode. Research suggests the methemoglobemia-induced characteristics of these compounds can result in mortality within $2 \mathrm{~h}$ of bait consumption in some species (i.e., stoats; Fisher et al. 2005).

\section{Feeding trials}

To screen potential mongoose toxicants, we conducted three sets of laboratory feeding trials to evaluate the efficacy and palatability of candidate toxicant formulations: 1) 5-day trials of 10 commercial rodenticide baits; 2) 1- and 3-day trials of technical diphacinone formulated in minced chicken; and 3) 1-day trials of various formulations of two alternative acute toxicants (PAPP and sodium nitrite) formulated in minced chicken. Mongooses were fasted (maintenance diet removed) $24 \mathrm{~h}$ prior to initiation of each trial. 
At the beginning of each feeding trial, maintenance diet was withheld from treatment animals. Trial diets were offered to treatment groups as specifically detailed above, while control groups continued to receive a dry cat food or minced chicken maintenance diet. All mongooses were checked daily (1-4 h intervals), and the cage floors were cleaned of fecal droppings and uneaten supplemental food. Excreta collection pan papers were replaced daily with new sheets.

Any spilled or uneaten test bait was collected and separated for weighing daily, and the feed hopper replenished with fresh bait as needed. Daily test food consumption was determined by subtracting the weight of uneaten bait (remaining in the feed hopper and spillage) from the amount offered for each day of the bait exposure periods.

All trials were approved by the USDA National Wildlife Research Center's Institutional Animal Care and Use Committee under research protocol QA-2196. Mongooses were exposed to test baits (1-5 days) during the regular work week (Mon-Fri, 0730-1600). Animal care and other maintenance tasks were conducted before $0900 \mathrm{~h}$ to maximize observation time during the rest of the day. Hourly bait status and health checks were conducted for acute and known fast-acting agents such as PAPP and sodium nitrite, and longer interval checks (4$6 \mathrm{~h}$ ) were performed for chronic agents. Post-feeding, mongooses were checked at least once per day during weekends and holidays and more frequently (2-3 times/day) upon observation of signs of toxicosis. Signs of toxicity were not anticipated during the first few days after anticoagulant bait consumption, particularly with first generation anticoagulants (diphacinone and chlorophacinone). Lethargy, inactivity and prostration are generally associated with anticoagulant toxicosis. Other signs may include cyanotic appearance, ataxia, and shallow/irregular breathing, followed by loss of consciousness and eventual death. Emesis (vomiting) was reported for mongooses (Keith et al. 1990, G. Ogura, University of Ryukyus, Okinawa, Japan, personal communication) in laboratory feeding trials with diphacinone and PAPP. We recorded bait status (consumption), emesis, listlessness, prostration, depth of breathing, response to vocal and/or external tactical stimuli, external bleeding (oral, nasal, anal, dermal), dark stool, bloody urine, and mortality.

The test bait was removed at the end of the bait exposure (1-5 days) period. Mongooses that died during the bait exposure period were weighed to determine post-treatment body mass. Surviving mongooses were maintained on the regular maintenance ration and water, and monitored for an additional 10-day post-treatment observation period. Mongooses that died during the 10-day observation period were weighed to determine post-treatment body mass and examined for external/orifice bleeding and pale/cyanotic oral cavity. Nonsymptomatic mortalities were further examined internally for signs of toxicosis. At the conclusion of the 10-day post-treatment observation period, all mongooses that did not succumb were euthanized.

\section{Results}

The only commercial bait that exceeded $50 \%$ mortality was Tomcat ${ }^{\circledR}$ Mouse and Rat Killer $0.01 \%$ bromethalin bait blocks, which achieved $100 \%$ mortality within 1 to 3 days of feeding (Table 2). To confirm this exceptional result, the trial was replicated with another 10 test animals. The second trial resulted in $90 \%$ mortality, for an overall efficacy rate of $95 \%$ with a test sample of 20 mongooses. The nine other commercial products resulted in a range from $10 \%$ (Boot Hill ${ }^{0} 0.005 \%$ bromadialone pellet packets) to three products achieving $50 \%$ overall mortality $\left(\operatorname{Terad}_{3}{ }^{\circledR} 0.075 \%\right.$ cholecalciferol bait blocks, Ramik ${ }^{\circledR}$ Green $0.005 \%$ diphacinone pellets, and Fast Draw ${ }^{\circledR}$ $0.0025 \%$ difethialone soft bait packs). The one rodenticide product co-registered for use on mongoose in Hawaii, Ramik@ Mini Bars $0.005 \%$ diphacinone blocks, achieved only $20 \%$ overall mortality.

In contrast, seven of the nine formulations with fresh minced chicken resulted in $\geq 50 \%$ mortality. The one-day feeding trial with $0.005 \%$ diphacinone technical material in minced chicken resulted in $70 \%$ mortality, and the three-day trial resulted in $100 \%$ mortality within 14 days. The only PAPP formulation that reached $100 \%$ mortality was the $0.15 \%$ concentration of the New Zealand product. The $0.15 \%$ Japanese formulation 2 achieved $80 \%$ mortality, though this difference from the New Zealand product of the same concentrations was not statistically significant $(p=$ 0.473 , Fisher's exact test). Lower concentrations of the New Zealand PAPP had reduced efficacy $(0.10 \%=70 \%, 0.075 \%=$ $50 \%$ mortality). Japanese formulation 1 of $0.15 \%$ PAPP achieved $50 \%$ mortality. Efficacy of both sodium nitrite formulations was poor, with $30 \%$ mortality from the dry powder version of the technical material and 10\% mortality from the peanut butter slurry version (see consumption data in Table 2). All mortalities from PAPP or sodium nitrite exposure occurred within $24 \mathrm{~h}$. Of the 35 mongooses that succumbed to PAPP, 20 (57\%) died within $1 \mathrm{~h}, 13(37 \%)$ between 1 and $4 \mathrm{~h}$ and $2(6 \%)$ within $24 \mathrm{~h}$. Of the four mongooses who succumbed to sodium nitrite, two $(50 \%)$ died within $4 \mathrm{~h}$ and $2(50 \%)$ within $24 \mathrm{~h}$.

Time to death was consistent with the mode of action for each toxicant. Mortalities resulting from ingestion of first generation anticoagulants (diphacinone and chlorophacinone), which require multiple feedings for an effective dose, occurred from days 3 to day 14 . Second generation anticoagulants (brodifacoum, bromadialone, and difethialone), capable of causing mortality with a single feeding, resulted in mortalities from days 2 to 10 . All mortalities associated with acute toxicants (bromethalin, PAPP, and sodium nitrite) occurred within 3 days, with the majority of mortalities occurring within $24 \mathrm{~h}$ of feeding. 


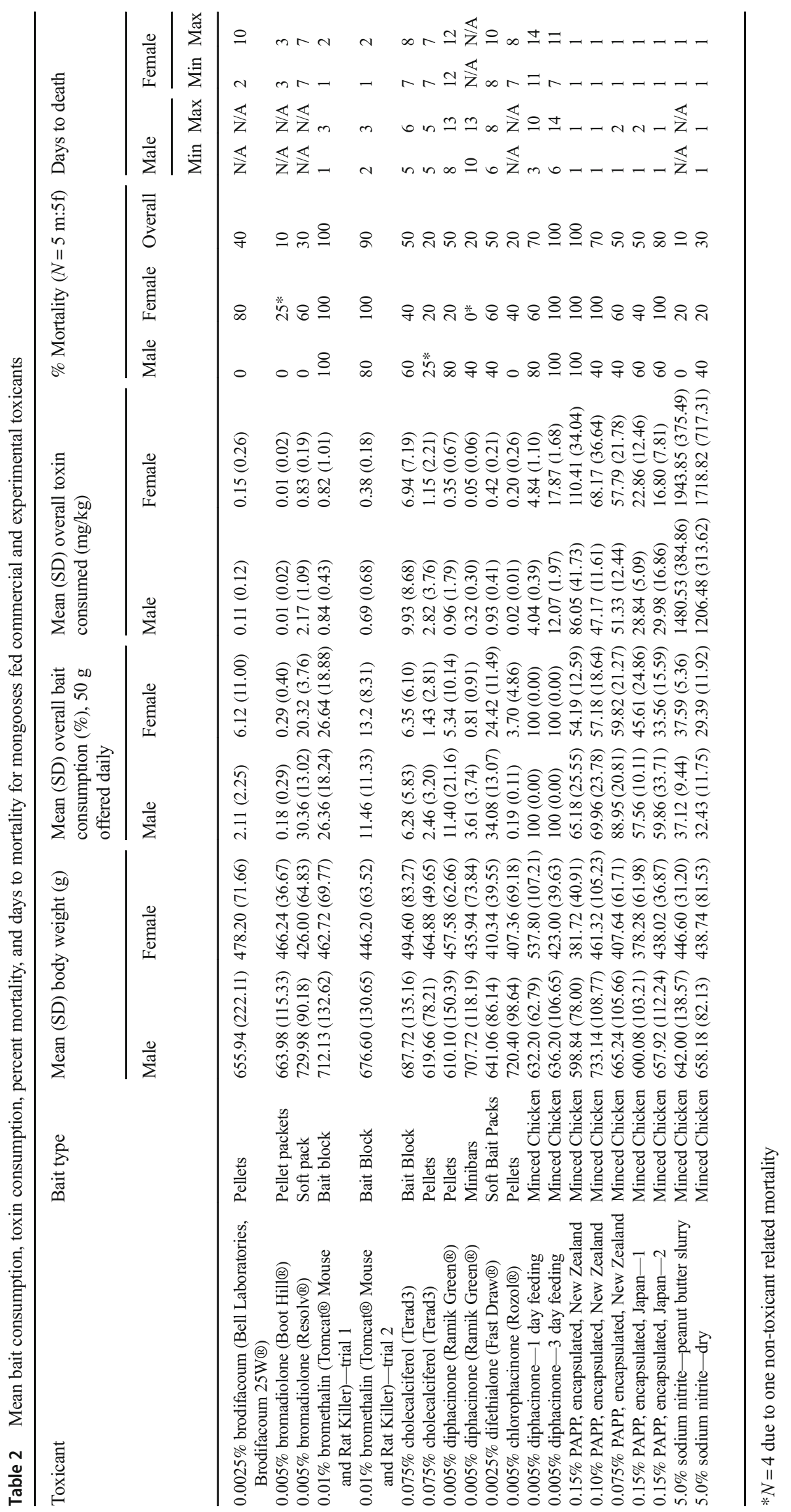


Three mongooses died from unknown causes; toxicant poisoning was ruled out due to little to no bait consumption prior to death and no signs of toxicosis upon post-mortem examination. It is possible that they perished as a result of difficulty adapting to a captive environment as evidenced by cage anxiety, poor feeding, and grooming behavior.

\section{Discussion}

The hard-textured grain-based pellet and block bait formulations, typical of most commercial first and second generation rodenticide baits, were poorly accepted by mongooses, with the sole exception of Tomcat ${ }^{\circledR}$ Mouse and Rat Killer bait blocks. Soft bait formulations of 2 second generation rodenticide baits (Resolv ${ }^{\circledR} 0.005 \%$ bromadiolone and Fast Draw ${ }^{\circledR} 0.0025 \%$ difethialone soft bait packs) were similar to the pellet/block bait formulations in poor palatability and efficacy.

In contrast, most baits formulated with fresh minced chicken were highly palatable to all mongooses in all trials with that bait substrate. Exceptions were the 5.0\% active ingredient minced chicken formulations (dry and peanut butter slurry) of encapsulated sodium nitrite where less than $20 \mathrm{~g}$ of bait were consumed. This poor bait acceptance is likely a result of the high sodium content (salty taste) (Cowled et al. 2008) which significantly altered (desiccated) the texture of the minced chicken within 3 to $4 \mathrm{~h}$ of bait preparation.

Mongooses are known to be highly susceptible to diphacinone toxicity (Keith et al. 1990), but the bait substrate currently used (i.e., hard, grain-based formulations) was less effective in inducing mortality than the same toxicant delivered in a food-based bait. This is not particularly surprising, as research suggests mongooses are more attracted to fresh foodbased attractants than to those that are grain-based or synthetic (Pitt and Sugihara 2008). The $0.005 \%$ diphacinone minced chicken bait effected 70 and $100 \%$ mortality in mongooses in the single- and three-day bait exposure periods, respectively. Not only did the diphacinone in fresh bait result in higher mortality rates than the currently registered product with the same active ingredient (20\% mortality), but fewer bait exposure days were required. The poor performance of the commercial diphacinone products we evaluated suggests they would likely be ineffective in controlling mongooses not because the toxicant is ineffective but because the bait is unpalatable.

There are several factors to consider when developing a bait formulation for toxicant delivery, including palatability, bait longevity, and non-target consumption. The ideal bait would be highly palatable to the target species and persist in the environment for a sufficient amount of time to be consumed in adequate amounts to affect control while limiting risks to non-target species. Fresh food baits are highly palatable to mongooses (Pitt and Sugihara 2008) but may also degrade rapidly due to consumption by invertebrates or other non-target species such as domestic cats (Felis catus), dogs (Canis lupus familiaris), and feral swine (Sus scrofa). Extensive exposure to humidity and moisture, such as rainfall in tropical environments, can cause baits to disintegrate rapidly (Howald et al. 2004; Berentsen et al. 2014) or mold (Dunlevy et al. 2000). Encasing the toxicant within a matrix such as paraffin can help improve bait longevity, but may reduce palatability. Use of fresh food baits in protective bait stations may reduce degradation while excluding some nontarget species. Further development of an effective toxicant for operational mongoose control should involve developing a mass-producible bait matrix (i.e., ground meat encapsulated in a protective skin/covering) that is attractive and palatable to mongooses and maintains integrity under harsh environmental conditions.

Relative toxicity to the target species is also an important factor to consider. Selecting a toxicant to which the target species is highly sensitive but is relatively benign to nontarget species is a challenge. In our study, sodium nitrite achieved $30 \%$ mortality with an average dose of 1206 $1943 \mathrm{mg} / \mathrm{kg}$, greater than the LD50 reported for rats (130$180 \mathrm{mg} / \mathrm{kg}$; Budavari 1989; Cowled et al. 2008). Studies evaluating the LD50 for sodium nitrite in mongooses are needed to more completely evaluate its potential use in mongoose control, particularly in areas where non-target exposure is a concern.

PAPP showed even greater promise, with up to $100 \%$ mortality in one formulation with doses ranging from 16 to $110 \mathrm{mg} / \mathrm{kg}$ of mongoose body weight, considerably lower than the LD50 reported for rats and other rodent species (Witmer 2013; Eason et al. 2014). Mongooses appear highly susceptible to PAPP and sodium nitrite but further research is required to determine appropriate concentrations and bait types.

We observed regurgitation $(\sim 5-20 \mathrm{~g})$ of partially digested PAPP bait (minced chicken) and generalized mucoid material by some mongooses. Of 50 mongooses offered PAPP across all treatment groups, 32 (64\%) regurgitated. Of these, $22(69 \%)$ perished and $10(31 \%)$ survived. In the $0.15 \%$ PAPP treatment that resulted in $100 \%$ mortality, $70 \%$ regurgitation was observed. Emesis also occurred with both formulations of sodium nitrite. Of 20 mongooses across both treatment groups, 5 regurgitated, of which 2 (50\% of all mortalities) succumbed. Whether regurgitation affected mortality remains unclear, particularly in the case of sodium nitrite where overall mortality was low.

Lastly, registration of a new pesticide product is a timeconsuming and costly process (Eason et al. 2010b). Extensive laboratory and field trials demonstrating $\geq 90$ and $\geq 70 \%$ efficacy, respectively, are required as well as thorough evaluation of environmental and non-target species risks 
(Jacobs 2011). In some regions, there is considerable demand for vertebrate pesticides for the protection of threatened and endangered species as well as protection of island ecosystems (Dickman 1996; Innes and Barker 1999; Courchamp et al. 2003; Parkes and Murphy 2003; Towns and Broome 2003); however, vertebrate pesticides still account for less than $0.1 \%$ of all pesticide use (Eason et al. 2010b). Limited market potential for vertebrate pesticides relative to the costs associated with development and registration of new products may be a financial limiting factor in in their development. However, the need for new control tools for vertebrate pest species, such as mongooses, remains high in agricultural and conservation regions. New control tools can allow wildlife managers to respond quickly in the event of accidental introductions or range expansions of vertebrate invasive species and to implement effective control programs for protection of human health and natural resources.

\section{Conclusion}

We identified and demonstrated the potential for development of three highly effective toxicants (PAPP, bromethalin and diphacinone) for mongooses in our laboratory trials. The currently registered dual species Ramik ${ }^{\circledR}$ Green diphacinone pellet and block baits were not effective against mongooses, despite the active ingredient (diphacinone) being highly effective when offered in a fresh, meat-based bait matrix. The sole commercial rodenticide product that showed promise was Tomcat ${ }^{\circledR}$ (bromethalin). However, this product is not currently labeled for use against mongooses and would require an EPA Special Local Needs (SLN) label and would likely require additional laboratory and field evaluations before the product could be labeled for use in mongoose control. The use of PAPP would require similar research. To this end, USDA NWRC sought and received startup funding to support the vetting of candidate toxicants for EPA registration potential, the reformulation of active ingredients into an attractive, palatable bait that can be efficiently and safely deployed in bait stations, and cage and placebo field trials to assess efficacy and bait uptake to support a potential EPA registration.

Acknowledgements The authors wish to thank K. Swift (Formerly United States Fish and Wildlife Service Pacific Islands Fish and Wildlife Office) for continued support in elevating the importance and impacts of mongoose predation on native avian species in Hawaii and the Pacific region. Thanks to T. Crabbe for assistance in the field, laboratory and data entry, and to T. Borneman for preliminary data proofing and summaries. Lastly, our sincere thanks to Shane Siers for his critical review and suggestions for improvements to earlier versions of this manuscript. This study was approved by the USDA National Wildlife Research Center's Institutional Animal Care and Use Committee under research protocol QA-2196.
Funding information Funding was provided by the United States Fish and Wildlife Service Pacific Islands Fish and Wildlife Office under Agreement \#F14PG00168.

\section{Compliance with ethical standards}

Conflict of interest statement The authors declare that they have no conflict of interest.

Disclaimer The use of trade or corporation names is for the convenience of the user in identifying products. Such use does not constitute an official endorsement or approval of any product by the U.S. Department of Agriculture.

\section{References}

Alicata JE (1958) A study of leptospirosis in Hawaii. Plantation Health 8: $505-512$

Alicata JE, Breaks V (1943) A survey of leptospirosis in Honolulu. Hawaii Med J 2:137-142

Baldwin PH, Schwartz CW, Schwartz ER (1952) Life history and economic status of the mongoose in Hawaii. J Mammal 33(3):335-356. https://doi.org/10.2307/1375771

Barun A, Hanson CC, Campbell KJ, Simberloff D (2011) A review of small Indian mongoose management and eradications on islands. In: Veitch CR, Clout MN, Towns DR (eds) Island invasives: eradication and management, IUCN, gland, Switzerland, pp 17-25

Barun A, Simberloff D, Budinski I (2010) Impact of the small Indian mongoose on native amphibians and reptiles of the Adriatic Islands, Croatia. Anim Conserv 13(6):549-555. https://doi.org/10.1111/j.1469-1795.2010.00374.x

Berentsen AR, Johnson SR, Gilbert AT, VerCauteren KC (2015) Exposure to rabies in small Indian mongooses (Herpestes auropunctatus) from two regions in Puerto Rico. J Wildl Dis 51(4):896-900. https://doi.org/10.7589/2015-01-016

Berentsen AR, Pitt WC, Eisemann JD, Engeman RM (2014) Longevity of rodenticide bait pellets in a tropical environment following a rat eradication program. Environ Sci and Pollut R 21(3):2283-2288. https://doi.org/10.1007/s11356-013-2148-1

Budavari S (1989) The Merck index, 11th edn. Merck \& Co., Rahway

Bryan EH Jr (1938) The much maligned mongoose. Paradise Pac 50(4): 32-34

Campbell TA (2012) Does a cost-effective feral swine-specific oral delivery system exist? 2012 wild pig conference science and management. San Antonio, Texas

Courchamp F, Chapuis JL, Pascal M (2003) Mammal invaders on islands: impact, control and control impact. Biol Rev 78(3): 347-383. https://doi.org/10.1017/S1464793102006061

Cowled B, Elsworth P, Lapidge S (2008) Additional toxins for feral pig (Sus scrofa) control: identifying and testing Achilles' heels. Wildl Res 35(7):651-662. https://doi.org/10.1071/WR07072

Dickman CR (1996) Impact of exotic generalist predators on the native fauna of Australia. Wildl Biol 2:185-195

Dunlevy PA, Campbell EW, Lindsey GW (2000) Broadcast application of a placebo rodenticide bait in a native Hawaiian forest. Int $\mathrm{J}$ Biodeter Biodeg 45:19-208

Eason CT, Miller A, MacMorran DB, Murphy EC (2014) Toxicology and ecotoxicology of para-aminopropriophenone (PAPP) - a new predator control tool for stoats and feral cats in New Zealand. New Zeal J Ecol 38:31-36

Eason C, Murphy E, Hix S, MacMorran D (2010a) Development of a new humane toxin for predator control in New Zealand. Integr Zool 1:31-36 
Eason C, Fagerstone K, Eisemann J, Humphrey S, O’Hare J, Lapidge S (2010b) A review of existing and potential New World and Australasian vertebrate pesticides with a rationale for linking use patterns to registration requirements. Int J Pest Manag 56(2):109125. https://doi.org/10.1080/09670870903243463

Everard COR, Everard JD (1992) Mongoose rabies in the Caribbean. Ann N Y Acad Sci 653(1 Tropical Vete):356366. https://doi.org/10.1111/j.1749-6632.1992.tb19662.x

Everard COR, Green AE, Glosser JW (1976) Leptospirosis in Trinidad and Grenada, with special reference to the mongoose. T Roy Soc Trop Med H 70(1):57-61. https://doi.org/10.1016/0035-9203(76)90008-0

Fisher P, O'Connor CE, Murphy EC (2005) Acute oral toxicity of paminopropiophenone to stoats (Mustela ermine). New Zeal J Zool 32(3):163-169. https://doi.org/10.1080/03014223.2005.9518409

Fisher P, O'Connor CE (2007) Oral toxicity of p-aminopropiophenone to ferrets. Wildlife Res 34(1):19-24. https://doi.org/10.1071/ WR06125

Hays WST, Conant S (2007) Biology and impacts of Pacific Island invasive species. 1. A worldwide review of effects of the Small Indian Mongoose, Herpestes javanicus (Carnivora: Herpestidae). Pac Sci 61(1):3-16. https://doi.org/10.1353/psc.2007.0006

Higa HH, Fujinaka IT (1976) Prevalence of rodent and mongoose leptospirosis on the Island of Oahu. Public Health Rep 91(2):171-177

Hoagland DB, Horst GR, Kilpatrick CW (1989) Biogeography and population biology of the mongoose in the West Indies. In: Woods CA (ed) Biogeography of the West Indies. Sandhill Crane Press, Gainesville, pp 611-634

Howald G, Samaniego A, Buckelew S, McClelland P, Keitt B, Wegmann A, Pitt WC, Vice DS, Campbell E, Swift K, Barclay S (2004) Palmyra Atoll rat eradication assessment, August 2004: trip report. Technical report to US Fish and Wildlife Service, Honolulu, HI, 61pp

Innes J, Barker G (1999) Ecological consequences of toxin use for mammalian pest control in New Zealand - an overview. New Zeal J Ecol 23:111-127

Jacobs WW, Jr (2011) Efficacy issues regarding control of commensal rodents in the US using registered rodenticides. US Environmental Protection Agency document EPA-HQ-OPP2011-0718-0011, 62pp

Keith JO, Hirata DN, Espy DL, Greiner S, Griffin D (1990) Field evaluation of $0.00025 \%$ diphacinone bait for mongoose control in Hawaii. USDA APHIS Denver Wildlife Research Center, unpublished final report, QA-16. 52pp

Lapidge S, Wishart J, Staples L, Fagerstone K, Campbell T (2012) Development of a feral swine toxic bait (Hog-Gone $\left.{ }^{\circledR}\right)$ and bait hoper (Hog-Hopper ${ }^{\mathrm{TM}}$ ) in Australia and the USA. Proc Wildl Damage Manag Conf 14:19-24

Lapidge S, Wishart J, Smith M, Staples L (2009) Is America ready for a humane feral pig toxicant? Proc Wildlife Damage Manage Conf. 13: $49-59$

Minette HP (1964) Leptospirosis in rodents and mongooses on the island of Hawaii. Am J Trop Med Hyg 13(6):826-832. https://doi.org/10. 4269/ajtmh.1964.13.826

Nellis DW, Everard COR (1983) The biology of the mongoose in the Caribbean. Stud Fauna Curacao Caribbean Isl 64:1-162

Parkes J, Murphy EC (2003) Management of introduced mammals in New Zealand. New Zeal J Zool 30(4):335-359. https://doi.org/10. 1080/03014223.2003.9518346

Phillips RB, Lucey B (2016) Kauai mongoose standard operating procedures to conduct and island-wide status assessment and early detection rapid response. US Fish and Wildlife Service, Pacific Islands Fish and Wildlife Office. Unpublished report, 25pp

Pimentel D (1955a) Biology of the Indian mongoose in Puerto Rico. J Mammal 36(1):62-68. https://doi.org/10.2307/1375723

Pimentel D (1955b) The control of the mongoose in Puerto Rico. A J Trop Med Hyg 4(1):147-151. https://doi.org/10.4269/ajtmh.1955.4.147
Pitt W (2008) Methdos and strategies to monitor and manage mammalian invasive species with special emphasis on rodents. Available at: https://www.aphis.usda.gov/wildlife_damage/nwrc/nwrc/WS Research_invasive_species.pdf

Pitt WC, Sugihara RT (2008) Evaluation of selected natural and artificial attractants, lures and bait substrates for attracting small Indian mongooses (Herpestes auropunctatus) to traps and activity stations in Hawaii. USDA APHIS WS National Wildlife Research Center, unpublished report: QA-1101, pp 33

Roy SS, Jones CG, Harris S (2002) An ecological basis for control of the mongoose Herpestes javanicus in Mauritius: is eradication possible? In Veitch CR, Clout MN (eds). Turning the tide: the eradication of invasive species. Proceedings of the International Conference on Eradication of Island Invasives, 19-23 February 2001, University of Aukland, Aukland. pp 266-273

Savarie PJ, Ping Pan H, Hayes DJ, Roberts JD, Dasch GL, Felton R, Schafer EW Jr (1983) Comparative acute oral toxicity of paraaminopropiophenone. B Environ Contam Toxicol 30(1):122-128. https://doi.org/10.1007/BF01610109

Smith DG, Polhemus JT, VanderWerf EA (2000) Efficacy of fish-flavored diphacinone bait blocks for controlling small Indian mongooses (Herpestes auropunctatus) populations in Hawaii. Elepaio 60:47-51

Sugihara RT, Pitt WC (2006) Screening trials to identify potential natural and artificial attractants, lures and bait substrates for introduce mongooses (Herpestes auropunctatus) in Hawaii. USDA APHIS WS National Wildlife Research Center, unpublished final report: QA-1101. 13pp

Tomich PQ (1986) Mammals in Hawaii $2^{\text {nd }}$ edition. Bishop museum special publication 76. Bishop museum press, Honolulu, Hawaii. 375 pp.

Tomich PQ (1979) Studies of leptospirosis in natural host populations. I. Small mammals of Waipio Valley, Island of Hawaii. Pac Sci 33:257-279

Towns DR, Broome KG (2003) From small Maria to massive Campbell: forty years of rat eradication from New Zealand islands. New Zeal J Zool 30(4):377-398. https://doi.org/10.1080/03014223.2003.9518348

Tvrtkovic N, Krystufek B (1990) Small Indian mongoose, Herpestes auropunctatus (Hodgson 1836) on the Adriatic islands of Yugoslavia. Bonn Zool Beitrage 41:3-8

U.S. Fish and Wildlife Service( 1999) Draft revised recovery plan for Hawaiian waterbirds, Second Revision. U.S. Fish and Wildlife Service Publication, Portland, Oregon, USA

Young LC, VanderWerf EA, Lohr MT, Miller CJ, Titmus AJ, Peters D, Wilson L (2013) Multi-species predator eradication within a predator-proof fence at Ka'ena point, Hawai'i. Biol Invasions 15(12):2627-2638. https://doi.org/10.1007/s10530-013-0479-y

Young LC, VanderWerf EA, Mitchell C, Yeun E, Miller CJ, Smith DG, Swenson C (2012) The use of predator proof fencing as a management tool in the Hawaiian islands: a case study of Ka'ena Point Natural Area Reserve. University of Hawaii at Manoa Pacific Cooperative Studies Unit, technical report 180. 88pp

Witmer G (2013) A preliminary evaluation of sodium nitrite as a rodenticide. QA-1752 final report. USDA/APHIS Wildlife Services, National Wildlife Research Center, Ft. Collins, CO.

Wong M, Katz AR, Li D, Wilcox BA (2012) Leptospira infection prevalence in small mammal host populations on three Hawaiian islands. Am J Trop Med Hyg. 87(2):337-341. https://doi.org/10.4269/ajtmh. 2012.12-0187

Yamada F, Sugimura K (2004) Negative impact of an invasive small Indian mongoose, Herpestes javanicus on native wildlife species and evaluation of a control project in Amami-Ohshima and Okinawa Islands. Jpn Glob Environ Res 8:117-124

Zieger U, Marson DA, Sharma R, Chikweto A, Tiwari K, Sayyid M, Lousin B, Goharriz H, Voller K, Breed AC, Werling D, Fooks AR, Horton DL (2014) The phylogeography of rabies in Grenada, West Indies, and implications for control. PLoS Negl Trop D. https://doi.org/10.1371/journal.pntd.0003251 